\title{
Delivering cognitive therapy for adolescent social anxiety disorder in NHS CAMHS: a qualitative analysis of the experiences of young people, their parents and clinicians- in-training
}

Article

Published Version

Creative Commons: Attribution 4.0 (CC-BY)

Open access

Taylor, L., Creswell, C., Pearcey, S., Brooks, E., Leigh, E., Stallard, P., Waite, P. ORCID: https://orcid.org/0000-00021967-8028, Clarke, D. M., Stephens, G. and Larkin, M. (2021) Delivering cognitive therapy for adolescent social anxiety disorder in NHS CAMHS: a qualitative analysis of the experiences of young people, their parents and clinicians-intraining. Behavioural and Cognitive Psychotherapy, 49 (4). pp. 398-412. ISSN 1352-4658 doi:

https://doi.org/10.1017/S1352465821000047 Available at https://centaur.reading.ac.uk/97203/

It is advisable to refer to the publisher's version if you intend to cite from the work. See Guidance on citing.

To link to this article DOI: http://dx.doi.org/10.1017/S1352465821000047

Publisher: Cambridge University Press 
All outputs in CentAUR are protected by Intellectual Property Rights law, including copyright law. Copyright and IPR is retained by the creators or other copyright holders. Terms and conditions for use of this material are defined in the End User Agreement.

\section{www.reading.ac.uk/centaur}

\section{CentAUR}

Central Archive at the University of Reading

Reading's research outputs online 


\title{
Delivering cognitive therapy for adolescent social anxiety disorder in NHS CAMHS: a qualitative analysis of the experiences of young people, their parents and clinicians-in-training
}

\author{
Lucy Taylor ${ }^{1, *}(\mathbb{D})$, Cathy Creswell ${ }^{2}(\mathbb{D})$, Samantha Pearcey ${ }^{2}$ (D) Emma Brooks $^{3}$ (D), Eleanor Leigh ${ }^{4}$ (D), \\ Paul Stallard ${ }^{5}$, Polly Waite ${ }^{2}$, David M. Clark ${ }^{4}$, , Gareth Stephens ${ }^{6}$ (i) and Michael Larkin ${ }^{7}$ (i) \\ ${ }^{1}$ Department of Psychiatry, University of Oxford, Warneford Hospital, Oxford OX3 7JX, UK, ${ }^{2}$ Department of Experimental \\ Psychology and Department of Psychiatry, University of Oxford, Anna Watts Building, Radcliffe Observatory Quarter, \\ Woodstock Road, Oxford OX2 6GG, UK, ${ }^{3}$ School of Psychology and Clinical Language Sciences, University of Reading, \\ Earley Gate, Whiteknights, Reading RG6 6AL, UK, ${ }^{4}$ Department of Experimental Psychology, University of Oxford, \\ Oxford Centre for Anxiety Disorders and Trauma, The Old Rectory, Paradise Square, Oxford OX1 1TW, UK, ${ }^{5} \mathrm{Child}$ and \\ Adolescent Mental Health Service, Oxford Health NHS Trust, Temple House, Temple Street, Keynsham, Bristol, BS31 \\ 1HA, UK, ${ }^{6}$ PPI representative, London, UK and ${ }^{7}$ Department of Psychology, Aston Triangle, Birmingham B4 7ET, UK \\ ${ }^{*}$ Corresponding author. Email: lucy.taylor@psych.ox.ac.uk
}

(Received 14 February 2020; revised 2 November 2020; accepted 18 December 2020; first published online 01 March 2021)

\begin{abstract}
Background: Social anxiety disorder (SAD) is common. It usually starts in adolescence, and without treatment can disrupt key developmental milestones. Existing generic treatments are less effective for young people with SAD than with other anxiety disorders, but an adaptation of an effective adult therapy (CT-SAD-A) has shown promising results for adolescents.

Aims: The aim of this study was to conduct a qualitative exploration to contribute towards the evaluation of CT-SAD-A for adoption into Child and Adolescent Mental Health Services (CAMHS).

Method: We used interpretative phenomenological analysis (IPA) to analyse the transcripts of interviews with a sample of six young people, six parents and seven clinicians who were learning the treatment. Results: Three cross-cutting themes were identified: (i) endorsing the treatment; (ii) finding therapy to be collaborative and active; challenging but helpful; and (iii) navigating change in a complex setting. Young people and parents found the treatment to be useful and acceptable, although simultaneously challenging. This was echoed by the clinicians, with particular reference to integrating CT-SAD-A within community CAMHS settings.

Conclusions: The acceptability of the treatment with young people, their parents and clinicians suggests further work is warranted in order to support its development and implementation within CAMHS settings.
\end{abstract}

Keywords: adolescents; CBT; CAMHS; IPA; psychological therapy; qualitative; social anxiety disorder; young people

\section{Introduction}

Social anxiety disorder (SAD) is characterised by an intense fear of social situations. It is the third most frequently diagnosed mental health disorder, and more than one in ten people will experience it during their lifetime (Beesdo et al., 2007; Kessler et al., 2005). SAD also has the lowest natural recovery rate of all anxiety disorders (Bruce et al., 2005). It usually starts in adolescence, and without treatment may disrupt key developmental milestones (e.g. educational achievement; Katzelnick and Greist, 2001).

(C) The Author(s), 2021. Published by Cambridge University Press on behalf of the British Association for Behavioural and Cognitive Psychotherapies. This is an Open Access article, distributed under the terms of the Creative Commons Attribution licence (https:// creativecommons.org/licenses/by/4.0/), which permits unrestricted re-use, distribution, and reproduction in any medium, provided the original work is properly cited. 
There is a clear need for effective treatments for adolescents to be available to mitigate these potentially negative lifelong consequences. It is important for these treatments to be deliverable within the NHS, in a way that clinicians, young people and their families find useful. This structural problem is complex, and it requires a methodological approach which can illuminate the meaning of an intervention, from a range of stakeholder perspectives, within a complex system.

Adolescents with SAD are typically offered generic cognitive behaviour treatments (CBT). However, recent studies have shown that 7 - to 17 -year-olds with SAD have lower remission rates from generic CBT approaches than those with other anxiety disorders (40\% vs $72 \%$ remission; (Ginsburg et al., 2011). For adults, disorder-specific cognitive therapy for SAD (CT-SAD) has demonstrated recovery rates of over 80\% (Clark et al., 2003; Clark et al., 2006; Clark et al., 2012), and is the recommended treatment for adult SAD (NICE, 2013). CT-SAD aims to reverse key psychological processes that are known to maintain SAD (Clark and Wells, 1995). Recent evidence suggests that the same psychological mechanisms maintain SAD in adolescents (Hodson et al., 2008; Leigh and Clark, 2018; Parr and Cartwright-Hatton, 2009; Schreiber et al., 2012). On this basis, CT-SAD has now been adapted for adolescents (CT-SAD-A). A recent case series reported recovery among all five young people who received treatment for severe levels of SAD (Leigh and Clark, 2016). Furthermore, a randomised controlled trial with adolescents identified in a school setting demonstrated that CT-SAD-A was superior to both a psychological placebo and a generic form of CBT on both self and clinician ratings at post-treatment (Ingul et al., 2014). Notably, some mechanisms of CT-SAD-A were not implemented fully in the study and other techniques not part of CT-SAD-A, such as psychoeducation, were used.

The promising results that have been achieved with CT-SAD-A have so far been obtained in a specialist setting, with a clinician with expertise in delivering cognitive therapy (Leigh and Clark, 2016). This combination is known to be a determinant in achieving good outcomes (Ginzburg et al., 2012). In order to evaluate the utility of this treatment for adoption into CAMHS (Child and Adolescent Mental Health Services), it is critical to establish whether CT-SAD-A can be effectively delivered within routine services. The CAMHS setting is complex, with a range of structural issues acting as barriers to the implementation of novel treatment approaches (Boston and Cottrell, 2016; Sayal et al., 2019).

A previous qualitative study of adults who received CT-SAD from experienced clinicians suggests that the approach is acceptable to - and valued as helpful by - people with social anxiety (McManus et al., 2010). 'Acceptability' in intervention development is often presented as a rather concrete and binary construct. In this study, we want to consider the acceptability of CT-SAD-A as something which becomes meaningful only when situated within a specific context (in this case, CAMHS), and which functions as an important component of implementation. It is important to understand how, why, for whom, and under what conditions, an intervention might be experienced as implementable and 'acceptable' (e.g. see Sekhon et al., 2017). Thus our study involves understanding the experiences of young people, their carers, and clinicians, and identifying insights into what helps or hinders the successful delivery of treatment. This knowledge can help us to determine the fit between CT-SAD-A and routine CAMHS settings. Qualitative work is often used to understand people's experiences of interventions and IPA has been used to explore such data (Black et al., 2018; Donnellan et al., 2013; Lundkvist-Houndoumadi and Thastum, 2017).

The aim of this study is to conduct a qualitative exploration of how CT-SAD-A (as delivered in Leigh et al. (linked article, an extract describing the treatment is included here ${ }^{1}$ ), is experienced

\footnotetext{
1'The treatment: CT-SAD-A, which is the adolescent version of CT-SAD for adults based on the Clark and Wells (1995) model, is a distinctive form of CBT delivered in 14 weekly 1.5 hour sessions provided on a one-to-one basis. CT-SAD-A involves: development of an individualised version of the Clark and Wells (1995) model; an experiential exercise to help patients discover the unhelpful effects of self-focused attention and safety behaviours; video feedback; systematic training in externally focused, non-evaluative attention; and behavioural experiments. When indicated, there may also be work on:
} 
within a CAMHS setting. To achieve this, we adopted a multi-perspective design, collecting qualitative data from young people, parents, and clinicians who were being trained to deliver the treatment.

\section{Method}

\section{Ethics and consent}

Ethical approval for this study was gained from the local NHS Research Ethics Committee (REC reference: 16/SC/0315). All participants gave informed consent/assent.

\section{Study approach and design}

We adopted an interpretative phenomenological analysis (IPA) approach (Smith et al., 2009), which has been used extensively to explore people's experiences of psychotherapy and mental health services, including adult SAD (McManus et al., 2010). This study uses a 'multiperspective' design (Larkin et al., 2018) to facilitate a fuller understanding of the treatment, and how it is experienced by patients, their parents, and clinicians.

\section{Participants and recruitment}

All clinicians $(n=7)$ who were being trained in CT-SAD-A alongside their usual practice, young people $(n=14)$ receiving it and their parents (see Leigh et al., linked paper), were invited to take part in this study (from two participating NHS Foundation Trusts: Oxford Health and Berkshire Healthcare). Eight young people and their families did not participate (one was still in treatment at the time of interviewing, one had moved abroad, two were uncontactable, and four declined to take part). All participants were offered $£ 20$ as compensation for their time.

\section{Sample}

Six young people, six mothers, and all seven clinicians consented to take part. Information about the participants is provided in Table 1, and in Appendix 1 in the Supplementary material. These have been treated as individual accounts and have not been analysed as triads to protect anonymity.

\section{Data collection and transformation}

Indicative topic guides were used (see Appendix 2 in the Supplementary material) for individual interviews conducted by study assessors or a research fellow with qualitative expertise, all trained and supervised by a specialist in qualitative research (M.L.). Interviews with young people were devised to be engaging and sensitive to the interpersonal and communicative preferences of this population. Interviews took place in person or over the telephone. All interviews were audiorecorded, transcribed verbatim and anonymised at the point of transcription.

The topic guides were developed by the research team, in consultation with our two expertsby-experience. In line with interviewing practices for IPA, we asked open questions, and prepared a flexible structure. This began by exploring participants' understanding of the problem, what they recalled about their expectations of therapy and their hopes for change. The main body of the questions focused on how people had experienced the therapy. We also used some visual

socially traumatic memories; anticipatory worry and post-event processing; low self-esteem; parental beliefs and behaviours; and bullying and its consequences. Further details of the treatment with case examples are described by Leigh and Clark (2016) and can also be found at www.oxcadatresources.com'. 
Table 1. Information about young people and clinicians

\begin{tabular}{llc}
\hline Young people & Diagnosis at post-treatment assessment \\
\hline Jane & Post-treatment not completed (only completed 2 sessions of CT) \\
James & None & Major depressive disorder \\
Julia & None & \\
Jade & None & Number of cases \\
Jennifer & Social anxiety disorder, specific phobia of spiders, depression \\
Jasmine & Professional background (all had at least 2 years & 2 \\
\hline & experience using CBT and working with young people) & $3(2$ fulla $)$ \\
Clinicians & Clinical psychologist & $0^{\text {b }}$ \\
\hline Caroline & Social worker & $2(1$ full) \\
Conner & Social worker & $3(2$ fulla) \\
Christopher & Clinical psychologist & 2 \\
Claire & Clinical psychologist & 2 \\
Carol & Social worker & \\
Camilla & CBT therapist (via adult IAPT) & \\
Charlotte & &
\end{tabular}

${ }^{\mathrm{a}} \mathrm{A}$ full course of treatment is delivery of at least 10 sessions.

${ }^{\mathrm{b}}$ This clinician attended the training workshops but did not deliver the intervention.

prompts (cards featuring different aspects of therapy) to help participants to think about issues which they might like to discuss. This worked well, and ensured that the interviewees were able to explore salient components of the therapy in some detail. At each stage we began by eliciting descriptions ('What kinds of things did you do in the sessions?') before prompting for more evaluative accounts ('How did you feel about that?'). Interviewers applied these principles flexibly, in order to prioritise active listening during the interviews, and allow participants' concerns to determine the direction and flow of discussion.

\section{Data analysis}

Analysis involved detailed coding in order to identify the experiences, claims and concerns of each participant (for more detail, see Larkin and Thompson, 2012), followed by the elaboration of emerging themes for each case. In keeping with a multiple perspective design, these themes were brought together at the level of each sub-sample group, before any form of betweensample synthesis was attempted. Coding for the three samples (young people, parents, clinicians) was led by three different members of the research team (E.B., S.P., L.T.) with supervision and comparative coding provided by M.L. The coding team worked together closely to compare both the organisation and format of their work, and the focus and plausibility of the codes themselves.

Two levels of analytic triangulation were used to monitor the credibility of the analysis (Yardley 2000). Firstly, in-depth triangulation was provided through co-analysis in supervision, to maintain a consistent focus to the coding. Secondly, broader triangulation focused on the appropriateness of the theme titles, persuasiveness and plausibility of the over-arching narrative, and intelligibility of the overall structure. This involved discussions with the Study Steering Committee and the Study Management Group, which included the patient and public involvement lead and a young person representative. The aim of this level was to check that the analysis is meaningful, useful and accessible.

\section{Researcher reflexivity and positioning}

The majority of the detailed coding was led by three team members. Themes were developed and discussed within a relatively large team of co-researchers. As such, it is not particularly useful to 
Table 2. Themes

\begin{tabular}{ll}
\hline Super-ordinate themes & Sub-ordinate themes \\
\hline Endorsing the treatment & $\begin{array}{l}\text { a. Hopeful and positive about the therapy and its outcomes } \\
\text { b. Clinicians' affinity with the treatment }\end{array}$ \\
$\begin{array}{ll}\text { active; challenging but helpful } & \text { a. Therapy is a collaborative effort } \\
\text { Navigating change in a complex setting } & \begin{array}{l}\text { b. An active process is challenging but helpful } \\
\text { c. Measuring progress is difficult, but supports guidance and learning }\end{array} \\
& \begin{array}{l}\text { a. The typical structure of CAMHS work prioritises crises over therapies } \\
\text { b. Complex cases require flexible responses }\end{array} \\
& \text { c. Practical problems impede implementation }\end{array}$ \\
\hline
\end{tabular}

provide individual reflections here, but it is worth noting some features of our groupwork. As a group, we were largely psychologists by training. Most team members did not have prior experience with this methodology. Some of us were also parents. Most team discussions about analysis involved facilitation from the one team member with extensive experience in this method. This combination of perspectives allowed for lots of open discussion and reflection in group meetings, and for consensus to develop about how we would manage issues such as additional knowledge about a given case, or discrepancies between perspectives. A useful way of thinking about these sorts of team discussions is provided by Vagle et al. (2009), who place Dahlberg's (2006) classic metaphor of phenomenological reflexivity ('bridling') in the context of group decision-making. The sense of the collective as a means of 'reigning in' run-away interpretations makes groupwork an excellent forum for this kind of analysis.

In IPA, the 'double hermeneutic' refers to the fact that researchers are interpreting participants' accounts, and that then, in those accounts, participants are themselves offering an interpretation of their own prior experience. This means that analysis focuses on participants' relationship to objects and events in a recalled world, interpreted for the 'now' that invoked by the context of the interview. Our interviewers were psychological researchers, and so we can assume that this set up some important contextual features for our participants. On the positive side, we might hope that being interviewed by a psychological researcher involves an expectation that it is OK to talk about thoughts and feelings. More problematically, we might wonder whether participants expected that researchers would not want to hear about challenges in a psychological therapy. If this was a barrier to open discussion, then respondents and interviewers did manage to overcome it to some extent. Themes 2 and 3 are evidence of this. It is possible, nevertheless, that some participants chose not to share some concerns with us, in this context.

\section{Results}

The analysis reported here focuses on expectations and experiences of the treatment from the perspective of young people, parents, and clinicians. The perspectives of these three groups cohere around the following super-ordinate themes (Table 2). The structure of the three over-arching themes means that we begin by reporting on the overall appraisal of the therapy (Endorsing the treatment), followed by an examination of the participants' perception of the therapy as helpful or otherwise (Finding therapy to be collaborative and active; challenging but helpful), and concluding with an exploration of some the contextual issues which shaped participants' experiences of the intervention (Navigating change in a complex setting).

\section{Endorsing the treatment}

(a) Hopeful and positive about the therapy and its outcomes

Young people and parents generally appeared to find the intervention acceptable. Largely positive expectations were often converted into positive reflections on gains. The therapy process itself was experienced as challenging but also helpful. 
A number of parents commented that the active, experiential approach of this treatment was a better fit for the young person than other, more dialogical approaches, such as counselling:

'He felt that it was more around, it was more experiential and it was more, um, er, of a pragmatic, practical, um, treatment programme, ... rather than sitting and just talking about what he knew were issues ... so, right from the outset, it felt different and, actually, never ever minded going.' [Paula $\left.{ }^{2}\right]$

Before starting CT-SAD-A, the idea of therapy was framed by some young people as very passive. For example, Jennifer described how she had expected to be 'sat in a room talking the whole time'. Others were more hopeful of practical benefits: 'learn some like, er, er, um techniques for them [the problems]' [James]. Some of the young people described feeling motivated by hope that the therapy would bring about improvements in their independence and confidence. They were attracted to the idea of a more interactive therapy:

'Instead of just like, you know, saying "Ahh I think I can get over it", just actually doing ... that seemed like quite a reasonable idea.' [Julia]

Parents mostly shared this sense of hope and were 'quite interested to see how it would [...] benefit' their child. The transition from expectations to consequences was generally consistent. After treatment, young people were able to identify areas of significant functional progress which were important to them. For example, James described several improvements since engaging in the therapy:

'I used to go to the support area, [...] for about three hours a day every school day. I haven't been in about a year ... I'd never put my hand up to answer questions, I wouldn't really go to lessons that much, er, but now I kinda answer questions all the time and talk to people and all that. [...] Performing was a big problem as well, but I, I do music now.' [James]

In general, parents were also very positive about the impact of the intervention in terms of what the young person was now able to do. Pippa reported that the improvements that her child had made were 'Leaps and bounds, very positive'. Parents reported improvements in the young persons' activities - particularly their engagement and involvement with friends, their autonomy and independence in communication, and their confidence in initiating activities outside of the house. One parent whose young person had a co-morbid diagnosis of depression was more hesitant with their endorsement of the treatment, and saw depression as a barrier: 'Probably her underlying depression wasn't you know, it wasn't being treated at that time and I think that restricted her access to the CBT' [Phoebe]. However, low mood was not always a barrier. For example, although one young person with low mood 'was quite worried about it [the treatment]' her parent reported that this worry was not fulfilled. On reflection, she thought 'it went very well ... and, now, the end result, it was so worth it' [Pippa].

In other cases, these were incremental changes, which one parent described as 'a very gradual process of, sort of, confidence' [Pamela], and could not be pinpointed to a specific time in treatment. However, by the end of treatment, these improvements stood out as markedly different from the pre-treatment phase. Parents reflected on the psychological changes which appeared to underpin these functional improvements. Pippa's account illustrates this:

'When she went in for her theory test, you know, she was like, um, like she said "I took a deep breath, thought; right, I can do this, nothing is going to happen, it's going to be fine" and, you

${ }^{2}$ Pseudonyms starting with 'P' denote parents, 'J' denote juniors (the young people) and 'C' denote the clinicians. 
know, it's those sort of things, like, that she, um, looks around her and her environment and takes it all in and knows that it's, it's okay.' [Pippa]

Here Pippa describes her child's ability to overcome difficult situations, by shifting her focus of attention to the external environment and drawing on learning from previous experiences ('nothing is going to happen'). As in this extract, there was generally a good sense that parents and young people had understood the ethos and principles of the intervention.

\section{(b) Clinicians' affinity with the treatment}

The therapists were positive about the training they received and the treatment itself, as illustrated here:

'It is a great model, I love it, I love it from a theoretical and technical point of view, erm, I love its application and how much success you can get with it.' [Conner]

The therapist manual (available from www.oxcadatresources.com) was appraised very positively, 'The manual was really, obviously a brilliant resource' [Carol], and some saw it very much as an integral part of growing their competence while delivering the intervention: ' $I$ was constantly referring back to it' [Caroline]. The clinicians looked forward to taking their new skills forward, both with social anxiety specifically and also transferrable skills:

'I think it has changed my practice a lot umm, not just with social anxiety, but I think with other treatments thinking about fidelity to the model umm behavioural experiments and how to develop a model umm, the attention training, the video feedback I think umm, not only in social anxiety cases where I feel a lot more confident and skilled in helping young people.' [Claire]

However, as will be discussed further below, they expressed concerns about whether CT-SAD-A was implementable within the current CAMHS context, which was consistently represented as 'really complex.' [Charlotte]

\section{Finding therapy to be collaborative and active; challenging but helpful}

(a) Therapy is a collaborative effort

The therapists were experienced as calm, friendly, and understanding. One young person commented, 'He was open [...] I could just talk for quite a long time and he wouldn't like judge me or anything.' [James]. The specific role of the therapist in establishing a collaborative relationship around the treatment seemed to be important to the young people. This is generally evident in the language used to report on these activities, which tended to highlight the collective voice:

'We looked at my umm behaviours and stuff that linked to it and then the things that I found the most umm, like, scary to do and then, after we went through them, we decided on things we could do that could like, get over them and then we coz-we were-it's quite easy to go to like shops and cafes and stuff and we just gradually built it up to things that I found the worst.' [Julia - underlining added to highlight collective voice]

It was also illustrated by examples of therapist modelling and engaging in activities. For example, James talked about how the '[Therapist] would stutter, er, then we'd see their reaction, but erm, yeah, he, he showed me that there wasn't, people didn't really care, to be honest with you if you stuttered.' [James] 


\section{(b) An active process is challenging, but helpful}

The young people recognised and appreciated the importance of the therapy as an active process of doing, rather than as just a space for talking and reflection. This is concisely illustrated here by Jade, talking about the behavioural experiments:

'I would go and interact with people outside, which I didn't like doing - but it was really, really helpful [pause] because [pause] just talking about it wouldn't have been enough.' [Jade]

During the interviews young people were provided with prompt cards listing the therapeutic mechanisms, and it was interesting that they consistently selected the same components as being important. They discussed these knowledgeably, and evaluated them in terms of their utility. For example, Julia was confident in identifying specific components as helpful:

'I definitely think the "training my attention" and the "behavioural experiments" were, like, key for me.' [Julia]

Parents similarly emphasised the active nature of behavioural experiments when identifying pertinent features of the intervention:

'It's very difficult to sit in a room for an hour and talk about yourself, I think, you know, to be able to go out and do those physical challenges, um, is probably a bit easier.' [Phoebe]

Clinicians also singled out behavioural experiments as a feature of the intervention that was particularly salient for their clinical work. For example, they were 'probably the most helpful' aspect of the intervention [Camilla], 'quite transformative' [Conner] and 'obviously a completely key part of it [that] the young people found ... really helpful and were then able to go away and then put it into practice' [Carol].

The benefits of the behavioural experiments were represented in terms of them being 'more active' than the therapists' usual ways of working.

'I was probably much more active than the CBT I was using before, I was probably much more passive [how do you mean?] Umm so right from the beginning you're adding behavioural experiments [oh okay yeah] where I probably wouldn't have done that before' [Claire].

We can thus see that young people, parents and clinicians reported behavioural experiments as the most salient and critical parts of the treatment. They were also widely reported as difficult for both the young person to complete and for the therapist to deliver. Despite their discomfort, people reported that behavioural experiments were one of the most helpful parts of their experience, and generally included both negative and positive aspects simultaneously when talking about them:

'I hated doing it, I absolutely hated it . . but that was probably my favourite bit because it did the most for me [...] I was so scared to do that as well, but it was nice to know at the end, like, I could do it. So I would say that was helpful, it was difficult at the time, but it was necessary I think.' [Jennifer]

'I just didn't like doing the things because I felt uncomfortable, but I see the, the whole point that we did it was to challenge the way I thought and it did.' [Jade] 
In these extracts, the challenging part of behavioural experiments is foregrounded in the affective language used to frame the activities ('absolutely hated', 'so scared to do that', 'I felt uncomfortable'). This serves to underscore the pay-off, in the participants' subsequent appraisals of benefit ('it did the most for me', 'it was necessary', 'I see the whole point that we did it'). The contrast illustrates the trust and bravery exhibited by the young people.

Parents were also aware that young people found some of the active aspects of treatment difficult:

'[The clinician] took her out and did practical things with her, which I thought was very good, much to [the young person], didn't like it, but it it helped her, you know. She probably thought that was the worst things for her to do, but actually doing it, it proved to her that it worked.' [Pippa]

Other features of the treatment could also be identified (e.g. attention training), but young people were less clear about how and why these components had been helpful. Clinicians also talked about less tangible benefits for attention training, and that it was 'hard to gauge how much a young person actually takes that on board' [Conner]. One therapist did report that despite initial doubts 'actually everyone seemed to engage well with it' [Carol]. Video feedback was more widely endorsed by the clinicians and was considered 'a very powerful part of the treatment' [Claire], helping to 'bring [...] alive the things we were talking about so that they could see it, rather than, just sit there and describe it' [Conner].

Alongside these very specific features of the treatment, there was also a strong sense that the young people felt that they were actively learning and developing skills in using a set of tools to help them think differently. Most young people were generally confident that they could identify what they learned, and could apply it. The importance of practice (outside of the sessions) seemed to underline this for most people. For example, one young person noted that 'remember[ing] all of the things [they'd] learned and then just keep going over it and over it' helped after the sessions had ended as 'then it didn't seem like such a difficult thing not having a session every week.' [Julia]. Some young people mentioned that the 'experiment sheets' were really helpful for this:

'I got given like experiment sheets to fill out and do the same things in between like say on my lunch break, umm, go and buy something myself from the shops coz I would never do anything like that umm and then I'd have to fill out these sheets and then bring them back to my next session.' [Jennifer]

\section{(c) Measuring progress is difficult, but supports guidance and learning}

A range of measures were completed on a weekly basis throughout treatment, completed at home and brought to each session. Some young people described how these 'kind of just became part of the treatment' [Jasmine]. The measures provided a focus for treatment (e.g. choice of a behavioural experiment), which the young people noticed and appreciated, as illustrated here by Julia:

'It meant that we could focus on specific things that were harder than others and I think that was quite useful because I don't think-, if-, I don't think, without the questionnaire, it would have been so obvious the things that needed to be worked on.' [Julia]

Additionally, the measures allowed young people to see their progress represented visually:

'It was quite useful cos you could see - you could compare the different things - what I'd done each week to see what I was progressing in and what I wasn't.' [Jasmine] 
One parent also commented on this, because 'you actually get to see it, of how she was feeling at that time and whether her mood was low or high' [Patricia]. For young people and parents, this positive feedback is both reassuring and informative - allowing them to consolidate learning or guiding their next steps. However, measures were also typically commented on by the young people as being difficult, 'really thick, dense and ... seem[ed] really, really daunting' [Jade], and 'tedious' [Julia] and that they took 'quite a long time' [Julia] to complete.

Clinicians tended to frame their concerns about the measures in terms of their perceptions of the young people's experiences of completing the measures; they worried that the young people found the measures to be boring, and therefore not helpful. Camilla, for example, felt that her clients were ' $a$ bit resistant to completing them' because they found them to be 'quite a chore'. Similarly, Carol felt that the young people found the measures to be ' $a$ bit of a pain'. As we have seen above, although young people did express concerns about the measures, they seemed, for the most part, to be acceptable to them, in light of their usefulness for guiding treatment and monitoring progress.

Aside from these seemingly misplaced concerns about the burdensome nature of the measures for the young people, clinicians singled out some as being particularly helpful clinically. Most preferred the anxiety-specific process measures ${ }^{3}$ which 'felt much more relevant' [Claire]. The social anxiety symptom measures were generally seen as the most useful, often in terms of their use in guiding treatment: 'kind of [to] do a comparison from week to week of what had changed and we'd pick things up' [Caroline]. Some therapists reflected on how they would make more use of measures in their future work, because of how useful they had been (e.g. Claire); others felt the burden of including the measures was not acceptable to them, because of the additional administrative load, although this was against the backdrop of their concerns about how the young people viewed them.

\section{Navigating change in a complex setting}

(a) The typical structure of CAMHS work prioritises crises over therapies

Therapists expressed a prevailing concern about implementing the treatment in a CAMHS context which was too 'stressful' to support this form of intervention. It was clear that the stress arose from a conflict with the time commitment required for learning and delivering the new therapy (i.e. where the structure required planning, preparation and regular timed activities), and the context of CAMHS (which required staff to respond to frequent acute crises). For example, Conner described how the stress arose from a tension between the intervention and 'everything else' in CAMHS.

'If you're working in a, kind of [pause] a day-to-day CAMHS clinic as opposed to a research clinic, it's more difficult, it's more stressful, in my perception um, in terms of the, the kind of conflict with everything else' [Conner]

Caroline presented these conflicts as being so entrenched that even if the evidence showed that the intervention was 'more effective' (than alternatives), 'the actual deployment of that in everyday clinical CAMHS would [pause] be less likely' [Caroline], suggesting that she would not be confident that it would be offered in CAMHS.

\footnotetext{
${ }^{3}$ Anxiety-specific process measures included: Social Cognitions Questionnaire, Social Behaviours Questionnaire. Social anxiety symptom measures included: Liebowitz Social Anxiety Scale. See linked paper, Leigh et al., for further details.
} 


\section{(b) Complex cases require flexible responses}

Therapists reflected that CAMHS services need to offer effective interventions for social anxiety and were positive about this treatment model: 'the model's great, I think the treatment is great' [Carol]. However, they worried that the majority of current CAMHS service-users would present with more complex problems than the clients with whom they worked within this study:

'I have massive admiration for it as a model and, and [...] it would be [...] life changing for many young people that do have social anxiety, that there's a kind of rub with um [pause] with the presentations that we see, I suppose.' [Conner]

'Typical CAMHS' cases were construed by all but one of the therapists as more complex (usually meaning 'with co-morbidities') and as presenting with more acute risk concerns. In some localities, cases were drawn from other CAMHS teams, or drawn up from Tier 2 services to Tier 3 (CAMHS) for this study. As such, the concern was sometimes based on an accurate perception that the young people would not currently meet the threshold for the therapists' usual service, or were not typical of those who would. The comments from Camilla and Conner here are typical of the concerns raised by all therapists:

'There is usually something that is co-morbid with it so umm, although it was, it appeared effective on social anxiety, there is other stuff going on for some people' [Camilla]

'Most young people who come into CAMHS have multiple problems some of which aren't clear diagnosis er kinda problems, but are more behavioural, or emotional, or kind of systemic in nature' [Conner]

The therapists were therefore keen to reflect upon how much flexibility would be required to deliver the intervention with more 'typical' service users, and to work out how much flexibility would be consistent with adherence to the model. On the whole, they spoke extensively about specific barriers and concluded that the model was not sufficiently flexible for CAMHS at present. However, some of these barriers (time, technology) may be more easily addressed than others (structure, complexity, as above).

\section{(c) Practical problems impede implementation}

Therapists' concerns about implementation were also evident in some very practical, structural features of the environment. CAMHS was configured to measure out time (clinical appointments, room bookings, etc.), in units of one hour. This meant that those delivering the intervention carried reduced caseloads ('Where's that time coming from?', Carol), due to the 'onerous [...] number of sessions [and] the length of the sessions, 90 minutes' [Conner]. This 'threw the diary structure' [Conner].

For example, the work involved in adhering to the therapeutic procedures was often presented as stressful to manage, and all therapists felt that they did not have sufficient time to meet these demands. For example, preparation time and supervision were more extensive than normal, and efforts to provide the therapists with additional time were undermined by the unpredictable nature of other routine work.

It should be noted that despite the difficulties reported by clinicians in the change to normal practice, the parents appreciated flexibility of the session length, appointment times, information about the young person's progress, and the opportunity for involvement in the therapy. As such, neither parents nor young people expressed very strong views about the CAMHS context of the therapy, and were typically relieved to be receiving treatment, notwithstanding the difficulty of accessing services and the 'really lengthy' referral process. 


\section{Discussion}

Although there were key differences in the context and stage of therapist training, the findings of this qualitative study found that, like adults (McManus et al., 2010), young people appeared to find some aspects of the intervention challenging, but they were happy to embrace this in light of the benefits that they brought. Overall, they experienced the clinicians to be open and nonjudgemental, and the therapeutic process to be active. The parents were similarly positive about their experience of CT-SAD-A, its active nature, and the clinicians who delivered it, despite the challenging aspects of it. The clinicians were also positive about the treatment and its utility, but they had a variety of concerns about implementing it in their CAMHS settings and the requirements of training in a new approach alongside their routine practice (e.g. dedicated case supervision, familiarisation with the manual, recording and reviewing therapy sessions) which may change once fully trained.

It was striking that clinicians struggled to reconcile their commitment to the therapy with their other commitments in the CAMHS setting. This tension resonates with the concepts of normalisation process theory, NPT (Murray et al., 2010). NPT is concerned with understanding how new ways of working can be integrated into routine care. The theory describes the mechanisms that have to be functioning before a new practice can be successfully implemented: coherence; cognitive participation; collective action; and reflexive monitoring. These mechanisms are enacted via a number of processes, the most critical of which is a shift from individual to collective action. From an NPT perspective, the theme 'Endorsing the Treatment' would appear to suggest that therapists perceived there to be coherence to the intervention itself, that clinicians monitored and valued outcomes, and that they endorsed and enacted the intervention with cognitive participation at the individual level. However, it was also evident that a full transition from individual to collective action was blocked by a number of barriers. The perception of a distinction between typical CAMHS cases and suitable treatment cases for clinicians learning the therapy undermined coherence. The demands of implementing all elements of the treatment in full, and the structural constraints involved in organising one's time and practice differently raised questions in the clinicians' minds about the possibility that these treatment practices could become 'normal' within CAMHS. The clinicians' experiences also suggested that the current structure of CAMHS is organised around dealing with acute crisis and this makes it difficult for therapists to manage structured and planned interventions. These issues are likely to present barriers to collective action, in a larger-scale implementation, unless they are addressed. A key question for service providers going forwards is what sort of models of service organisation would allow CAMHS to be more able to support therapists in delivering structured, evidence-based therapies such as CT-SAD-A.

The impact of both the structural and physical barriers (e.g. technology issues, session length, conflicting demands, protecting time) on clinicians' experience of delivering a new treatment should not be under-estimated (Boston and Cottrell 2016; Sayal et al., 2019). Keeping this in mind, the feedback from the clinicians and young people around completing measures for the intervention is interesting. Sessional measures are an important component of CT-SAD-A, requiring engagement by both the clinician and the young person. Clinicians appeared to focus on the idea that the young people found them a chore to complete, which was true, but as we have seen this was offset by their perceived utility. Within NPT, this experiential information could be used as communal appraisal to reflect on the activity from different viewpoints, to allow a fuller understanding of its worth, and to help to make the administrative burden acceptable. This finding contributes to the wider current debate around the implementation of routine outcome measurements (ROMs), often viewed with scepticism by clinicians, with only $6.8 \%$ of a sample of CAMHS clinicians routinely collecting sessionby-session outcome measures (James et al., 2015). However, when we listen to young people's 
and clinicians' views of session-by-session ROMs we find that their acceptability is associated with their perceived helpfulness, as in the case of CT-SAD-A here.

In addition to the use of measures to guide the focus of treatment, the other main way that clinicians felt that CT-SAD-A differs from other therapies is the very active nature of some of the components. Our analysis suggests that the most salient feature of the treatment for all interviewees was the behavioural experiments. It is worth noting that young people were consistently able to pick these, and other, distinct therapeutic mechanisms out and were able to discuss and evaluate them knowledgeably: this is not always the case in studies of therapeutic experience. This clear understanding of their valuable utility ('coherence' to continue the NPT resonance), by young people, parents and clinicians appear to be key to their commitment to an activity that requires effortful work to do. For both measures and behavioural experiments, this reflection on being 'difficult, but good' is useful for monitoring and supporting their promotion by clinicians which might otherwise be lost in the logistical challenges of implementation.

From a methodological point of view, the interpretations of the complex responses that this type of qualitative work yields underlines the importance of including these types of methods to examine acceptability of the treatment. Other methods, such as a rating scale, might have only detected the negative appraisal ('I hated it') of the behavioural experiments, whereas we were able to detect further evaluative reflection of the benefits. Nonetheless, this study was not without its limitations. The young people formed a somewhat homogeneous group of white British females in the upper half of the age range for which this treatment is suitable. However, this was also useful as the variation of their rich accounts were less likely to be due to gender or age differences. Where there were anomalies in the accounts, a more nuanced view may have been possible if the three perspectives (young people, parent, clinician) could have been analysed as a triad. This was not possible as anonymity had been assured at the outset.

The multi-perspective approach was at the same time a strength of the study, allowing different experiences to contribute towards an explanation of a particular phenomenon that would otherwise not have been available, as with the differing accounts of using the measures. Another strength of this study is that the clinicians delivering CT-SAD-A were regular CAMHS clinicians in the pragmatic setting of a routine CAMHS service, and the issues they talked about were likely to reflect the issues of a wider implementation. It should be noted that each clinician in this study only delivered the treatment twice, so some of the implementation issues would probably not endure were the clinicians to become more expert in delivering CT-SAD-A.

\section{Conclusion}

The analysis of the accounts presented here highlight the need and potential utility for treatments such as CT-SAD-A, but equally the need for clinicians to be able to deliver it without feeling like they are compromising their other commitments within the current structure of CAMHS. It is a credit to all the clinicians who were learning CT-SAD-A in the study that the resulting frustrations were utterly concealed from the parents and young people who spoke so highly of them.

\footnotetext{
Supplementary material. To view supplementary material for this article, please visit: https://doi.org/10.1017/S13524658 21000047
}

Data availability. Due to difficulties fully anonymising this qualitative dataset we regret that data cannot be made available.

Acknowledgements. We would like to express wholehearted thanks to the families and clinicians who took part in this study. We are grateful for the invaluable contributions of our PPI representatives. 
Financial support. This work was supported by the National Institute of Health Research (NIHR HTA 14/170/01; NIHR Research Professorship; C. Creswell; Senior Investigator (D.M. Clark)); Wellcome Trust (Clinic Research Fellowship (E. Leigh); Programme Grant (D.M. Clark).

Conflicts of interest. David M. Clark is an author of the cognitive model of social anxiety that CT-SAD-A is based on and played a central role in developing CT-SAD. No other conflicts of interest are declared.

Ethics statements. All authors have abided by the Ethical Principles of Psychologists and code of Conduct as set out by the BABCP and BPS. Ethical approval for this study was gained from the local NHS Research Ethics Committee (REC reference: 16/SC/0315).

\section{References}

Beesdo, K., Bittner, A., Pine, D. S., Stein, M. B., Höfler, M., Lieb, R., \& Wittchen, H. U. (2007). Incidence of social anxiety disorder and the consistent risk for secondary depression in the first three decades of life. Archives of General Psychiatry, 64, 903-912.

Black, P., Hanna, D., Quinn, P., \& Dyer, K. (2018) Examining the experience of undergoing group cognitive behavioral therapy for obsessive compulsive disorder: an interpretative phenomenological analysis. International Journal of Group Psychotherapy, 68, 195-203. doi: 10.1080/00207284.2017.1403852

Boston, P., \& Cottrell, D. (2016). Trials and tribulations - an RCT comparing manualized family therapy with treatment as usual and reflections on key issues that arose in the implementation. Journal of Family Therapy, 38, 172-188.

Bruce, S. E., Yonkers, K. A., Otto, M. W., Eisen, J. L., Weisberg, R. B., Pagano, M., Shea, M. T., \& Keller, M. B. (2005). Influence of psychiatric comorbidity on recovery and recurrence in generalized anxiety disorder, social phobia, and panic disorder: a 12-year prospective study. American Journal of Psychiatry, 162, 1179-1187.

Clark, D. M., Ehlers, A., Hackmann A., McManus, F., Fennell, M., Grey, N., Waddington, L., \& Wild, J. (2006). Cognitive therapy versus exposure and applied relaxation in social phobia: a randomized controlled trial. Journal of Consulting and Clinical Psychology, 74, 568.

Clark, D. M., Ehlers, A., McManus, F., Hackmann, A., Fennell, M., Campbell, H., Flower, T., Davenport, C., \& Louis, B. (2003). Cognitive therapy versus fluoxetine in generalized social phobia: a randomized placebo-controlled trial. Journal of Consulting and Clinical Psychology, 71, 1058.

Clark, D. M., \& Wells, A. (1995). A cognitive model of social phobia. Social Phobia: Diagnosis, Assessment, and Treatment, 41, 00022-23.

Clark, D. M., Wild, J., Grey, N., Scott, R., Liness, S., Deale, A., et al. (2012). Self-Study enhances the effects of cognitive therapy for social anxiety disorder: a randomized controlled trial. Pre-Publication report registration: ISRCTN11178360. 20122109.

Dahlberg, K. (2006) The essence of essences - the search for meaning structures in phenomenological analysis of lifeworld phenomena. International Journal of Qualitative Studies on Health and Well-being, 1, 11-19. doi: 10.1080/174826 20500478405

Donnellan, D., Murray, C., \& Harrison, J. (2013). An investigation into adolescents' experience of cognitive behavioural therapy within a child and adolescent mental health service. Clinical Child Psychology and Psychiatry, 18, 199-213. doi: $10.1177 / 1359104512447032$

Ginsburg, G. S., Kendall, P. C., Sakolsky, D., Compton, S. N., Piacentini, J., Albano, A. M., Walkup, J. T., Sherrill, J., Coffey, K. A., \& Rynn, M. A. (2011). Remission after acute treatment in children and adolescents with anxiety disorders: findings from the CAMS. Journal of Consulting and Clinical Psychology, 79, 806.

Ginzburg, D. M., Bohn, C., Höfling, V., Weck, F., Clark, D. M., \& Stangier, U. (2012). Treatment specific competence predicts outcome in cognitive therapy for social anxiety disorder. Behaviour Research and Therapy, 50, 747-752.

Hodson, K. J., McManus, F. V., Clark, D. M., \& Doll, H. (2008). Can Clark and Wells' (1995) cognitive model of social phobia be applied to young people? Behavioural and Cognitive Psychotherapy, 36, 449-461.

Ingul, J. M., Aun, T., \& Nordahl, H. M. (2014). A randomized controlled trial of individual cognitive therapy, group cognitive behaviour therapy and attentional placebo for adolescent social phobia. Psychotherapy and Psychosomatics, $83,54-61$.

James, K., Elgie, S., Adams, J., Henderson, T., \& Salkovskis, P. (2015). Session-by-session outcome monitoring in CAMHS: Clinicians' beliefs. The Cognitive Behaviour Therapist, 8 (E26).

Katzelnick, D. J., \& Greist, J. H. (2001). Social anxiety disorder: an unrecognized problem in primary care. Journal of Clinical Psychiatry, 62 suppl 1, 11-15; discussion 15-16.

Kessler, R. C., Berglund, P., Demler, O., Jin, R., Merikangas, K. R., \& Walters, E. E. (2005). Lifetime prevalence and age-ofonset distributions of DSM-IV disorders in the National Comorbidity Survey Replication. Archives of General Psychiatry, 62, 593-602. 
Larkin, M., Shaw, R., \& Flowers, P. (2018). Multiperspectival designs and processes in interpretative phenomenological analysis research. Qualitative Research in Psychology, 16, 182-198. doi: 10.1080/14780887.2018.1540655

Larkin, M., \& Thompson, A. R. (2012). Interpretative phenomenological analysis in mental health and psychotherapy research. Qualitative Research Methods in Mental Health and Psychotherapy, 101-116.

Leigh, E., \& Clark, D. M. (2016). Cognitive therapy for social anxiety disorder in adolescents: a development case series. Behavioural and Cognitive Psychotherapy, 44, 1-17.

Leigh, E., \& Clark, D. M. (2018). Understanding social anxiety disorder in adolescents and improving treatment outcomes: applying the cognitive model of Clark and Wells (1995). Clinical Child and Family Psychology Review, 1-27.

Lundkvist-Houndoumadi, I., \& Thastum, M. (2017). Anxious children and adolescents non-responding to CBT: clinical predictors and families' experiences of therapy. Clinical Psychology and Psychotherapy, 24, 82-93. doi: 10.1002/cpp.1982

McManus, F., Peerbhoy, D., Larkin, M., \& Clark, D. M. (2010). Learning to change a way of being: an interpretative phenomenological perspective on cognitive therapy for social phobia. Journal of Anxiety Disorders, 24, 581-589.

Murray, E., Treweek, S., Pope, C., MacFarlane, A., Ballini, L., Dowrick, C., Finch, T., Kennedy, A., Mair, F., O’Donnell, C., Ong, B. N., Rapley, T., Rogers, A., \& May, C. (2010). Normalisation process theory: a framework for developing, evaluating and implementing complex interventions. BMC Medicine, 8, 63.

NICE: National Institute for Health and Care Excellence (2013). Social anxiety disorder: recognition, assessment and treatment. Clinical guideline [CG159]. Retrieved from: https://www.nice.org.uk/guidance/cg159 (accessed 7 February 2019).

Parr, C. J., \& Cartwright-Hatton, S. (2009). Social anxiety in adolescents: the effect of video feedback on anxiety and the self-evaluation of performance. Clinical Psychology and Psychotherapy: An International Journal of Theory and Practice, 16, 46-54.

Sayal, K., Roe, J., Ball, H., Atha, C., Kaylor-Hughes, C., Guo, B., Townsend, E., \& Morriss, R. (2019). Feasibility of a randomised controlled trial of remotely delivered problem-solving cognitive behaviour therapy versus usual care for young people with depression and repeat self-harm: lessons learnt (e-DASH). BMC Psychiatry, 19, 42.

Schreiber, F., Höfling, V., Stangier, U., Bohn, C., \& Steil, R. (2012). A cognitive model of social phobia: applicability in a large adolescent sample. International Journal of Cognitive Therapy, 5, 341-358.

Sekhon, M., Cartwright, M., \& Francis, J. J. (2017). Acceptability of healthcare interventions: an overview of reviews and development of a theoretical framework. BMC Health Services Research, 17, 88. doi: 10.1186/s12913-017-2031-8

Smith, J., Flowers, P., \& Larkin, M. (2009). The Theoretical Foundations of IPA. In Interpretive Phenomenological Analysis: Theory, Method and Research, pp. 11-39.

Vagle, M. D., Hughes, H. E., \& Durbin, D. J. (2009). Remaining skeptical: bridling for and with one another. Field Methods, 21, 347-367. doi: 10.1177/1525822X09333508

Yardley, L. (2000). Dilemmas in qualitative health research. Psychology and Health, 15, 215-228.

Cite this article: Taylor L, Creswell C, Pearcey S, Brooks E, Leigh E, Stallard P, Waite P, Clark DM, Stephens G, and Larkin M (2021). Delivering cognitive therapy for adolescent social anxiety disorder in NHS CAMHS: a qualitative analysis of the experiences of young people, their parents and clinicians-in-training. Behavioural and Cognitive Psychotherapy 49, 398-412. https://doi.org/10.1017/S1352465821000047 